\title{
Functional improvement after subthalamic stimulation in Parkinson's disease: a non-equivalent controlled study with 12-24 month follow up
}

\author{
M Capecci, R A Ricciuti, D Burini, V G Bombace, L Provinciali, M lacoangeli, M Scerrati, \\ M G Ceravolo
}

See Editorial Commentary, p 759

J Neurol Neurosurg Psychiatry 2005;76:769-774. doi: 10.1136/jnnp.2004.047001

\begin{abstract}
See end of article for authors' affiliations

.....................

Correspondence to: Dr M G Ceravolo, Clinica di Neuroriabilitazione, Dipartimento di Neuroscienze Universitò Politecnica delle Marche, Via Tronto 10-60020 Torrette-Ancona, Italy; cl.neuroria@univpm.it
\end{abstract}

Received 7 June 2004 Revised version received 9 December 2004 Accepted

22 December 2004
Objective: This study aimed to assess the effectiveness of chronic bilateral STN-S in improving the functional status of PD patients compared with patients treated with drugs alone.

Methods: Controlled study of disability index changes over 12 and 24 month chronic STN stimulation. Of 39 patients with advanced PD meeting CAPSIT criteria for STN-S, 23 underwent surgery; 16 patients decided against surgery and continued on drug schedule adjustments. Functional status was measured using the Activities of Daily Living section of the Unified Parkinson's Disease Rating Scale (UPDRS-ADL), Brown's Disability Scale, and Functional Independence Measure. UPDRS motor score and subscores for selected items, levodopa equivalent daily dose, and Beck Depression Inventory scores were also monitored.

Results: T12 follow up data were available for all 39 patients and T24 data for 13 STN-S and 8 control subjects. Compared with controls, STN-S patients experienced significant or highly significant improvements in all independence measures at both 12 and 24 months (time $\times$ treatment effect T12: $F=19.5, p=0.00008 ; T 24: F=6.2, p=0.005$ ). Forward stepwise regression for independent predictors of the yearly rate of UPDRS-ADL score modification in the entire sample showed that treatment was the only factor significantly associated with functional status change (beta coefficient $-0.54, t$ value -2.5 , $p=0.02$ ), whereas other variables - UPDRS motor score, BDI, and age at disease onset and enrolmentwere not in the equation.

Conclusion: STN-S is an effective therapeutic option in advanced PD. It induced a consistent improvement of functional abilities over two years to an extent that was not achieved with drug therapy alone.
B ilateral chronic subthalamic nucleus stimulation (STN-S) is an effective treatment ${ }^{1-3}$ for the symptomatic control of advanced Parkinson's disease (PD). The surgical approach is highly resource intensive and thus requires extensive documentation to support its effectiveness and safety. ${ }^{4}$ Adequate study designs and a more comprehensive assessment, evaluating the patient's point of view and changes in functional status as well as symptom relief, have been recommended..$^{6-8}$

Our investigation aimed to assess prospectively the overall impact of chronic bilateral STN-S on the functional status of patients with PD; disability indices were monitored in a cohort of patients with PD treated with drugs alone.

\section{METHODS}

\section{Design of the study}

Non-equivalent pretest-post-test control group study of disability changes over 12 and 24 months chronic STN stimulation.

\section{Patient selection}

Patients were eligible for the study if they met the internationally agreed criteria for deep brain stimulation. ${ }^{9}$ Hence we enrolled patients with advanced PD if they showed clinical fluctuations or side effects from drug therapy leading to moderate to severe disability and were no longer having significant advantages from drug scheduling adjustments. Patients who met the requirements of the Core Assessment Program for Surgical Interventional Therapies in Parkinson's disease $(\text { CAPSIT })^{10}$ and gave informed consent to the operation were considered as cases (STN-S group). Those patients who decided against surgery acted as controls.

\section{Primary outcome}

We employed a uniform structured assessment protocol which included both generic (Activity of Daily Living section of the Unified Parkinson's Disease Rating Scale ${ }^{11}$ (UPDRSADL)) and disease specific measures of disability (Brown's self-assessment Disability Scale (B'DS) ${ }^{12}$ and the Functional Independence Measure (FIM), ${ }^{13}$ which was administered by a certified specialist). Because the UPDRS-ADL is considered conceptually unsound by some researchers, ${ }^{14}$ a separate statistical analysis was also performed by pooling the UPDRS-ADL disability subscores (that is, speech, handwriting, cutting food, dressing, hygiene, turning in bed, and gait) according to the procedure described by Hariz et al..$^{15}$ The $\mathrm{B}^{\prime} \mathrm{DS}$ is a specific and reliable self-evaluation questionnaire addressing domains of instrumental performances and provides information on the difficulties experienced by patients in ADL and leisure activities. The score ranges from 0 (no disability) to 100 (worst possible condition). FIM-the most widely applied scale of disability-focuses on care needs, scoring them from 18 (complete dependence) to 126 (full independence). We included this scale to gain insight into the relative impact of PD on functional status using domains that are usually applied to non-PD individuals with disabilities.

Abbreviations: BDI, Beck Depression Inventory; B'DS, Brown's selfassessment Disability Scale; CAPSIT, Core Assessment Program for Surgical Interventional Therapies in Parkinson's disease; FIM, Functional Independence Measure; $H / Y$, Hoehn and Yahr; LEDD, levodopa equivalent daily dose; PD, Parkinson's disease; STN-S, subthalamic nucleus stimulation; UPDRS-ADL, Unified Parkinson's Disease Rating Scale Activities of Daily Living 
Since advanced PD is characterised by motor fluctuations, the patients' functional abilities may vary even within the same day, ranging from a very poor to a nearly "normal" condition. For all three scales, scores were given by asking patients how they usually (that is, most times) performed each activity during the day.

\section{Secondary outcome}

We considered the overall impact of chronic STN-S on neurological status (that is, the cardinal signs and symptoms of the disease) as secondary outcome and used the UPDRS-III for assessment because this scale addresses motor signs. The neurological status of all the patients included in the study was evaluated both in "defined-OFF" and "defined-ON" medication condition ${ }^{10}{ }^{16}$ at T0, T12, and T24; in the STN-S group, the patients were assessed after surgery both in ON Stim-OFF Med and in ON Stim-ON Med conditions.

We studied the occurrence and severity of given motor symptoms such as postural reflex, gait, freezing, drooling, speech, falls, and dyskinesias separately using the relevant UPDRS subscores; the daily rate of OFF-hours was also recorded in both groups. The self-evaluation Beck Depression Inventory $(\mathrm{BDI})^{17}$ was administered to monitor mood. In addition, the patients underwent a structured neuropsychological assessment aimed at excluding cognitive impairment in the mnesic, attentive, visuospatial, executive, praxic, and language domains. ${ }^{18-24}$ We also calculated the total levodopa equivalent daily dose (LEDD). ${ }^{25}$

\section{Assessment procedure}

A standard battery of clinical, cognitive, and functional tests was administered at the time of assessment for eligibility (T0), and at 12 (T12) and 24 (T24) months by researchers experienced in scale administration. The results of previous evaluations were not available to either patients or raters. Interobserver variability in functional scale ratings was assessed before the study using analysis of variance for repeated measures and obtaining reproducibility index values greater than 0.80 for the UPDRS-ADL, UPDRS-III, and FIM scores.

\section{Management of the patients}

The neurosurgical procedure applied in the STN-S group has been previously described by Capecci et $a^{26}$; we followed Volkmann et $a^{27}$ recommendations for the adjustment of the drug schedule and electrical parameters.

The controls continued to be treated via adjustments in drug therapy and non-pharmacological strategies according to the international guidelines for advanced PD management ${ }^{28}{ }^{29}$ based on a problem solving approach. ${ }^{30}$ Patients were seen at intervals of at least three months to address emerging problems and adopt appropriate management strategies.

\section{Data analysis \\ Group comparability}

Baseline personal, clinical, and functional characteristics were compared with unpaired $t$ tests for parametric data (age, disease duration, LEDD) and the Mann-Whitney U test for non-parametric data (UPDRS score and subscores, daily rate of OFF hours, and the remaining functional scale scores).

\section{Primary outcome}

To check for differences in the evolution of the functional status between the two groups, we included the disability scores as dependent variables in a two way analysis of variance for repeated measures, comparing the functional trends of the two groups of patients and considering time and treatment effects both separately and cumulatively.

To control for possible confounding variables related to personal or clinical characteristics, we also assessed the strength of the relation between all the possible determinants of functional status and the annual modification rate of each disability index. This rate was computed according to the equation: $\left(\right.$ Score $_{\mathrm{T} 0}-$ Score $_{\mathrm{T} 12}$ )/Score ${ }_{\mathrm{T} 0}{ }^{*} 100$ ), and was used as the dependent variable of a forward stepwise regression analysis aimed at extrapolating predictive factors of functional evolution. Independent variables other than group allocation (that is, surgical $v$ conservative approach) added to the regression model were: age at enrolment, age at disease onset, T0 scores for UPDRS-ADL, BDI, UPDRS-motor section and UPDRS items postural reflex, gait, freezing, drooling, speech, falls, and dyskinesias. The independent variables were individually added or deleted from the model at each step of the regression (depending on $F$ to enter $(=0.0001$ ) or $F$ to remove $(=0.0))$ until the "best" regression model was obtained.

\section{Secondary outcome}

We monitored the secondary outcome indices in both groups and analysed these using descriptive statistics. We made within group comparisons using a paired $t$ test for parametric data and Wilcoxon's test for non-parametric data. "Time $x$ treatment" effects were investigated using two way analysis of variance for repeated measures.

All analyses were performed using the Statistica for Windows (STAT-SOFT, 1993) package.

\section{RESULTS}

Between July 2000 and July 2002, 426 patients with PD (219 men and 207 women; mean (SD) age 58.9 (10.8) years, range 38-79; mean disease duration 8.45 (5.7) years, range 1-22) were referred to the movement disorders outpatient centre of our department for counselling, adjustments in drug therapy, or rehabilitation. There were 276 patients $(64.8 \%)$ with Hoehn and $\mathrm{Yahr}^{31}(\mathrm{H} / \mathrm{Y})$ stage III-IV.

Although we enrolled 294 cases with disease related disability, most could not be considered for surgery due to the following reasons: symptom duration $<5$ years $(n=19)$; age $>70$ years $(n=127)$; dementia $(n=84)$; non-drug related major behavioural disorders $(n=23)$; concomitant cerebrovascular disease $(n=41)$; and other non-neurological diseases (that is, severe comorbid diseases, or cardiac pacemaker or other devices preventing magnetic resonance examination; $\mathrm{n}=96$ ).

Overall, 42 patients with advanced PD (H/Y stage III-IV) underwent a structured evaluation following the CAPSIT recommendations. Since three were not eligible for STN-S because of MRI evidence of brain atrophy or subcortical vascular lesions, 39 patients were finally included in the STN-S group. Of these, 23 ( 12 men and 11 women; mean age 59.5 (7.5) years, mean disease duration 12.8 (4.2) years; median $\mathrm{H} / \mathrm{Y}$ stage IV) underwent surgery within two months (mean 45 (12) days) of enrolment (STN-S group); the remaining 16 patients (six men and 10 women, mean age 62.2 (6.5) years; mean disease duration 10.3 (4.2) years; median $\mathrm{H} / \mathrm{Y}$ stage IV) decided against surgery, mainly because of fear of operation and served as controls. However, four of these patients then changed their minds and underwent surgery 13, 14, 16, and 17 months after enrolment, thus withdrawing from the study. Their data are included in the 12 month follow up results only.

T12 (mean 12 (1.2) months) follow up data were available for all 39 patients and T24 (mean 24 (1.7) months) data for 13 STN-S patients and eight controls. The baseline characteristics of the patients who completed T24 follow up were as 


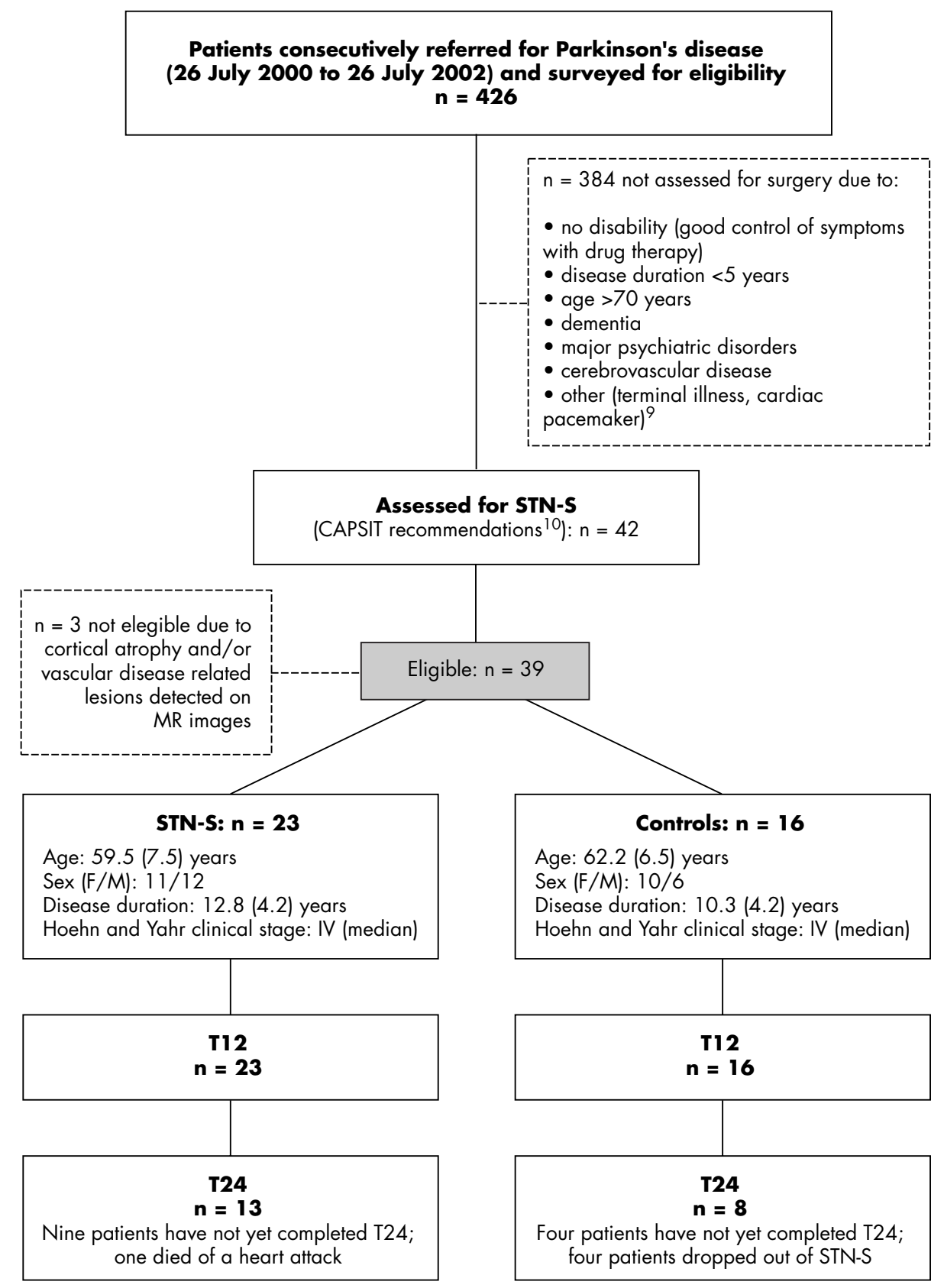

Figure 1 Flow of patients through the study, and the demographic and clinical data of the enrolled patients. STN-S, subthalamic nucleus stimulation.

follows: the STN-S group had seven women and six men (age 58.1 (6.8) years; disease duration 12.2 (4.1) years; median $\mathrm{H} / \mathrm{Y}$ stage IV (range III-IV)) and the control group had six women and two men (age 62.2 (7.7) years; disease duration 8.4 (2.0) years; median $\mathrm{H} / \mathrm{Y}$ stage IV (range III-IV)). One STN-S patient died of a heart attack 18 months after surgery, four controls dropped out after T12 to undergo surgery, and 13 subjects have not yet completed T24. The flow of patients through the study is shown in fig 1 .

Between group comparisons ruled out differences in baseline clinical, demographic and functional data. Surgical complications were observed in two patients: one had a right capsulothalamic haemorrhage leading to mild left hemiparesis (motricity index: upper limb 75\%; lower limb 80\%) and one developed infection at the site of the pulse generator, which healed with antibiotics. Data on these patients were included in the outcome analysis according to an intention to treat basis.

\section{Evolution of functional status}

In the STN-S group all disability indices improved at T12 as measured by a decrease in the UPDRS-ADL score of $\sim 52 \%$ $(\mathrm{p}<0.00001)$ with respect to T0, which was preserved at T24; in the controls this score showed a non-significant trend towards deterioration at both time points. Two way analysis of variance yielded a significant "time $\times$ treatment" effect in the STN-S compared with the control group (T12: $F=19.5$; $\mathrm{p}=0.00008$; $\mathrm{T} 24: F=6.2 ; \mathrm{p}=0.005)$. The separate analysis of UPDRS-ADL disability item confirmed the effectiveness of STN-S in improving functional outcome in PD patients (time $\times$ treatment effect T12: $F=8.8 ; \mathrm{p}=0.005 ; \mathrm{T} 24: F=13.2$; $\mathrm{p}=0.00004)$. The B'DS score improved both at T12 and T24; the "time $\times$ treatment" effect was significant (T12: $F=11.8$; $\mathrm{p}=0.002 ; \mathrm{T} 24: F=6.5 ; \mathrm{p}=0.007)$. STN stimulation induced a non-significant increase in the FIM score at T12 and T24, whereas the "time $\times$ treatment" effect was significant (T12: 
Table 1 Trends in the mean (SD) of the primary outcome measures in the two groups and results of two way analysis of variance for the strength of the cumulative "time $x$ treatment" effect (this included the main effect of between groups (comparison between groups at each time) and repeated measures (comparison over time of individual scores) factors

\begin{tabular}{|c|c|c|c|c|c|c|c|c|}
\hline \multirow[b]{2}{*}{ Time point (no of cases) } & \multicolumn{3}{|l|}{ STN-S } & \multicolumn{3}{|l|}{ Controls } & \multicolumn{2}{|c|}{ Time $\times$ treatment $p$ value } \\
\hline & T0 (23) & T12 (23) & T24 (13) & T0 (16) & T12 (16) & T24 (8) & $\mathrm{T} 12$ & T24 \\
\hline UPDRS-ADL & $16.6(4.1)$ & $8.0(4.6)$ & $10.6(3.3)$ & $14.4(4.7)$ & $14.9(6.0)$ & $16.3(7.9)$ & 0.00008 & 0.005 \\
\hline UPDRS-ADL disability items & $12.5(2.5)$ & $6.4(5.2)$ & $6.6(4.4)$ & $8.6(2.7)$ & $8.5(3.1)$ & $10.4(4.1)$ & 0.005 & 0.00004 \\
\hline$B^{\prime} D S$ & $41.8(23.4)$ & $18.3(11.6)$ & $19.0(13.5)$ & $35.3(15.5)$ & $41.9(26.4)$ & $42.8(25.6)$ & 0.002 & 0.007 \\
\hline FIM & 108.2 (17.9) & $117.6(4.8)$ & $118.2(4.6)$ & 113.6 (9.4) & 106 (11.5) & $101.2(16)$ & 0.04 & 0.04 \\
\hline
\end{tabular}

UPDRS-ADL disability items is a composite subtotal of scores from: speech, handwriting, cutting food, dressing, hygiene, turning in bed, and gait. B'DS, Brown's Disability Scale; FIM, Functional Independence Measure; STN-S, subthalamic nucleus stimulation; UPDRS-ADL, Unified Parkinson's Disease Rating Scale for Activity of Daily Living.

$F=4.7 ; \mathrm{p}=0.04 ; \mathrm{T} 24: F=3.6 ; \mathrm{p}=0.04)$ due to the deteriorating scores of controls. The mean trends of primary outcome measures in the two groups are given in table 1 .

\section{Change in neurological status}

After surgery, both motor symptoms and daily rates of OFFperiods were markedly reduced in all patients. The improvement in UPDRS motor score in "defined-OFF" condition was $\sim 53 \%$ at T12 (UPDRS-III: T0 $=38.3(11.6)$, T12 = 17.9 (11.7); Wilcoxon's test, $\mathrm{z}$ score $4.2 ; \mathrm{p}=0.0001)$ and was preserved at T24 (UPDRS-III: 18.0 (4.7)) (table 2).

The daily OFF-period rate decreased by $90 \%$ in all 23 STN-S patients. In particular, clinical items from different UPDRS sections showed highly significant reductions: rate of dyskinesia ( $\mathrm{z}$ score $4.0 ; \mathrm{p}<0.0001$ ), tremor ( $\mathrm{z}$ score 4.3; $\mathrm{p}<0.0001$ ), and sensory symptoms (z score: $3.9 ; \mathrm{p}<0.0001$ ), whose scores tended to 0 in all subjects. The change was significant for axial symptoms such as gait ( $\mathrm{z}$ score 3.8; $\mathrm{p}<0.001$ ), freezing ( $\mathrm{z}$ score $2.6 ; \mathrm{p}<0.01$ ) and falls ( $\mathrm{z}$ score 2.0 ; $\mathrm{p}=0.04)$, whose scores decreased although not uniformly among the patients. Speech disorders and drooling were unaffected (see table 2). No significant changes in the "OFF" UPDRS motor score were recorded in controls at any time during the study, whereas the OFF daily rate exhibited a progressive increase (by $\sim 25 \%$ at T24: Wilcoxon's test, $\mathrm{z}$ score 1.9; $\mathrm{p}<0.05$ ) ( see table 2 ).

In the STN-S group, LEDD was significantly reduced at T12 $(\mathrm{T} 0=987.9 \quad(427.0) \mathrm{mg} ; \mathrm{Tl} 2=708.0 \quad$ (311.0) mg; paired $t$ test, 5.3; $\mathrm{p}<0.0001)$ and showed a further, though nonsignificant, decrease at 24 months (T24 $=561.0$ (347.0) $\mathrm{mg}$ ); in controls it remained unchanged throughout the study (time $\times$ treatment effect: $F=4.5 ; \mathrm{p}<0.05$ ).
Mood tended to improve at T12 in STN-S patients, whose mean BDI score decreased from 14.4 (6.9 to 9.5 (2.6) (Wilcoxon's test $\mathrm{z}$ score $2.3 ; \mathrm{p}=0.02$ ) and remained stable at T24 (9.5 (4.1)); in the control group changes were not significant (mean BDI scores: T0 $=13.5$ (6.4), T12 $=10.5$ (4.9), T24 = 8.5 (4.9); Wilcoxon's test, not significant) (see table 2). Neuropsychological assessment ruled out the onset of dementia in all subjects during follow-up.

\section{Predictors of functional scale score deterioration}

Stepwise regression analysis was performed only on T12 data, due to the small T24 sample.

First, the analysis sought independent predictors of annual modification in the UPDRS-ADL score UPDRS $_{\mathrm{T} 0}-\mathrm{UPDRS}_{\mathrm{T} 12} /$ UPDRS $\left._{\mathrm{TO}}{ }^{*} 100\right)$ in the whole population. The following variables were introduced in the model: age at enrolment; age at disease onset; baseline UPDRS-ADL and UPDRS-III scores, and subscores for postural reflex, gait, freezing, drooling, speech, falls, and dyskinesias; BDI score; and treatment.

The analysis extrapolated surgical treatment (beta coefficient $-0.54 ; t$ value $-2.5 ; \mathrm{p}=0.02$ ) as the main independent predictor of the decrease in the disability score $(\mathrm{R}=0.48$; $\mathrm{R}^{2}=0.23 ;$ adjusted $\mathrm{R}^{2}=0.16 ; F=3.2440 ; \mathrm{p}<0.05 ; \mathrm{SE}$ of estimate 26.4). Among the other variables, only the UPDRS "falls" subscore was in the equation, although it did not achieve significance in predicting functional evolution at T12.

When the analysis employed B'DS score change as a dependent variable, the findings overlapped with those already obtained with the UPDRS-II scale, showing an independent predictive value of "treatment" in the forward stepwise regression (beta coefficient -0.99 ; $t$ value -5.1 ;

Table 2 Trends of secondary outcome measures in the two groups and results of two way analysis of variance for the strength of the cumulative "time $\times$ treatment" effect

\begin{tabular}{|c|c|c|c|c|c|c|c|c|}
\hline \multirow[b]{2}{*}{ Time point (no of cases) } & \multicolumn{3}{|l|}{ STN-S } & \multicolumn{3}{|l|}{ Controls } & \multicolumn{2}{|c|}{$\begin{array}{l}\text { Time } \times \text { treatment } \\
\text { p value }\end{array}$} \\
\hline & TO (23) & $\mathrm{T} 12(23)$ & T24 (13) & TO (16) & $\mathrm{T} 12$ (13) & T24 (8) & $\mathrm{T} 12$ & T24 \\
\hline UPDRS-III OFF (mean (SD)) & $38.3(11.6)$ & $17.9(11.7)$ & $18.0(4.7)$ & $37.4(5.1)$ & $39.8(6.3)$ & $41.7(7.9)$ & $<0.0000$ & 0.001 \\
\hline UPDRS-III ON (mean (SD)) & $10.2(8.2)$ & $11.7(8.7)$ & $13.5(8.5)$ & $12(9.2)$ & $13(5.4)$ & $14(5.8)$ & NS & NS \\
\hline OFF daily rate mean ((SD)) & $46.1(1.8)$ & $5.9(6.4)$ & $5.2(6.3)$ & $38.1(15.5)$ & $42.1(4.6)$ & $45.8(8.9)$ & $<0.0000$ & 0.0001 \\
\hline Rate of dyskinesia (median (quartiles)) & $2(1-3)$ & $0(0-1)$ & $0(0-1)$ & $1(1-2)$ & $2(1-2)$ & $2(1-3)$ & 0.00008 & 0.01 \\
\hline Drooling (median (quartiles)) & $0(0-1)$ & $0(0-1)$ & $1(0-1)$ & $0(0-1)$ & $0(0-1)$ & $1(0-1)$ & NS & NS \\
\hline Speech (median (quartiles)) & $2(1-2)$ & $1(0-2)$ & $2(1-3)$ & $0(0-1)$ & $0(0-1)$ & $1(0-2)$ & NS & NS \\
\hline Tremor (median (quartiles)) & $2(1-3)$ & $0(0-1)$ & $0(0-1)$ & $1(1-2)$ & $1(1-2)$ & $2(1-2)$ & 0.0001 & 0.001 \\
\hline Gait (median (quartiles)) & $2(1-2)$ & $1(0-1)$ & $1(1-2)$ & $1(1-2)$ & $2(1-2)$ & $2(1-2)$ & 0.01 & 0.05 \\
\hline Freezing (median (quartiles)) & $2(0-3)$ & $1(0-2)$ & $1(1-2)$ & $1(1-2)$ & $2(1-2)$ & $1(1-2)$ & 0.04 & NS \\
\hline Postural reflex (median (quartiles)) & $2(1-2)$ & $1(0-2)$ & $1(1-2)$ & $1(0-1)$ & $1(0-2)$ & $1(0-2)$ & 0.007 & 0.007 \\
\hline Falls (median (quartiles)) & $0(0-1)$ & $0(0-0)$ & $0(0-0)$ & $0(0-1)$ & $0(0-0)$ & $1(0-1)$ & 0.05 & NS \\
\hline Sensory symptoms (median (quartiles)) & $2(1-2)$ & $0(0-0)$ & $0(0-1)$ & $1(1-2)$ & $2(1-3)$ & $2(1-2)$ & 0.0001 & 0.001 \\
\hline LEDD (mean (SD)) & $987.87(427.0)$ & $708.0(311.0)$ & $561.0(347.0)$ & $961.19(474.0)$ & $1032.4(356.6)$ & $922.5(289.1)$ & 0.0005 & 0.05 \\
\hline $\mathrm{BDI}($ mean $(\mathrm{SD}))$ & $14.4(6.9)$ & $9.5(2.6)$ & $9.5(4.1)$ & $13.5(6.4)$ & $10.5(4.9)$ & $8.5(4.9)$ & NS & NS \\
\hline
\end{tabular}


$\mathrm{p}=0.00009)$. As regards FIM score modifications, the regression analysis did not identify any predictive factor among those introduced in the model.

\section{DISCUSSION}

STN-S has consistently been shown to attenuate the motor symptoms of $\mathrm{PD}$ and to decrease the daily dosage of medication, thus reducing drug related motor complications and, according to some reports, relieving attendant disability. $^{2}{ }^{3125}{ }^{252-34}$ In fact, the few studies addressing the overall impact of chronic neuromodulation on functional status fail to provide conclusive results owing to inconsistent disability assessment tools and the lack of control data about disease course without surgery. ${ }^{35}$

The case-mix in our study can be considered as representative of Parkinson's outpatients referred to specialised movement disorder centres for counselling, as it included a large proportion of patients with advanced disease compared with samples from general practice described in community based studies. ${ }^{36}{ }^{37}$ The rates of fluctuations, dyskinesias, behavioural disturbances, and dementia substantially overlap with literature reports. ${ }^{38} 39$

In our study, a significant functional improvement was recorded irrespective of the disability index applied as dependent variable. In particular, the UPDRS-ADL score improved by approximately $52 \%$ and B'DS by $56 \%$, whereas the FIM score increased by about $8 \%$ from baseline. The benefits observed at T12 were preserved at T24.

These improvements, which are in line with the literature in terms of both extent and direction, ${ }^{232}$ are even more striking if compared with the slight but clear deterioration experienced by control patients. Better results have been obtained $^{9250}$ using the Schwab and England scale ${ }^{41}$; however, though routinely applied by neurologists, its clinometric properties have never quite been established. ${ }^{14}$

We chose not to discriminate between functional status in $\mathrm{ON}$ and OFF conditions because the evaluation of ADL disability requires a comprehensive measure, as recently pointed out by Goetz and coworkers in laying down the recommendations for UPDRS-ADL administration. ${ }^{42} 43$ The ADL section of UPDRS is health specific, valid, reliable, and widely used, despite the charges of poor construct validity for mixing impairment with disability domains. ${ }^{144}$ In this context, Hariz and coworkers extrapolated the items regarding functions from those assessing impairments. ${ }^{15}$ In the present study, separate analyses of the total UPDRS-ADL score and of the composite subscore according to these authors failed to yield different results, thus confirming the overall positive impact of STN-S on the multiple aspects of PD related disability.

Our interest in appraising independence via patient selfassessment led us to adopt Brown's scale. This tool-albeit reliable and good at evaluating disease specific disabilities throughout illness progression ${ }^{12}{ }^{45}$-is heavily dependent on patients' views of their abilities and, ultimately, influenced by their tendency to underestimate their difficulties. ${ }^{45}$ We included it especially with the aim of excluding the expectation bias of the raters, who could not be blinded to group allocation; on the other hand, we considered that the typical patients' expectation bias would have worn off by the time of the yearly assessments.

The FIM is a generic tool that barely captures disability arising from the motor impairment typical in patients with PD (that is, not absence but slowness of movement). It showed a "ceiling effect" possibly accounting for the modest changes observed in our patients.

Although comparison of the results obtained in the STN-S group with the evolution of the condition observed in control subjects strengthens the case for the surgical option, the fact that patients were not randomised may have influenced our findings. The choice of a non-equivalent design was dictated by the fact that it would have been difficult and unethical to delay by two years a treatment whose efficacy in controlling motor symptoms is firmly established. ${ }^{82}$ The decision to monitor clinical evolution without interfering with the timing of surgery may thus have introduced a bias. To counter it, we tried to see whether, after excluding differences in the baseline features of the patients from the two groups, any independent variables other than treatment could explain the variance of disability indices and affect intragroup differences. The stepwise regression analysis confirmed the key role of chronic STN neuromodulation, whose impact exceeded that of any other clinical predictor.

Mood strongly affects the functional status of patients with a chronic disease. ${ }^{46}$ Depression is a frequent complication of $\mathrm{PD}^{47}{ }^{48}$ possibly enhanced by STN-S, ${ }^{49-51}$ that has also been charged with increasing suicide risk. ${ }^{52}$ In the present study, BDI scores improved significantly in STN-S patients from T0 to T12 and T24 and did not change in the control group. Secondary outcome analysis confirmed the symptomatic relief provided by chronic STN-S, which was reflected in a significant reduction in both UPDRS-III scores and global amount of medication (LEDD) taken, with figures comparable to those reported in other studies. ${ }^{25} 3240$ The improvement observed at 12 months was preserved at two years and was achieved independently of either disease duration or severity, in line with a recent report demonstrating that amount of preoperative levodopa complications did not influence postoperative outcome. ${ }^{53}$

The results of this study argue for taking the surgical option in advanced PD. However, estimating the final impact of this strategy on the overall disease burden should also take into account the proportion of patients eligible for STN-S. Based on internationally accepted criteria, ${ }^{9}{ }^{10}$ less than $10 \%$ of all PD patients consecutively referred to our movement disorders centre between July 2000 and July 2002 and 13\% of those with disease related disability were eligible for surgery. Advanced age, dementia, and concurrent illness were the commonest causes of exclusion.

\section{Conclusion}

Our investigation shows that selected patients with advanced PD benefit significantly from chronic STN neuromodulation, with consistent and stable improvements in motor and functional abilities compared with patients managed with drugs alone. No available pharmacological option is currently capable of affecting functional status to the same extent. ${ }^{4854-56}$ Specific, rather than generic, disability scales are reliable and comprehensive tools to measure treatment outcomes. In particular, the UPDRS-ADL scale proved to be a sensitive evaluation tool capable of reflecting the multifaceted aspects of functional impairment associated with PD. Community based cost-benefit appraisal studies are needed to confirm the impact of surgical treatment on the social and economic burden of disease.

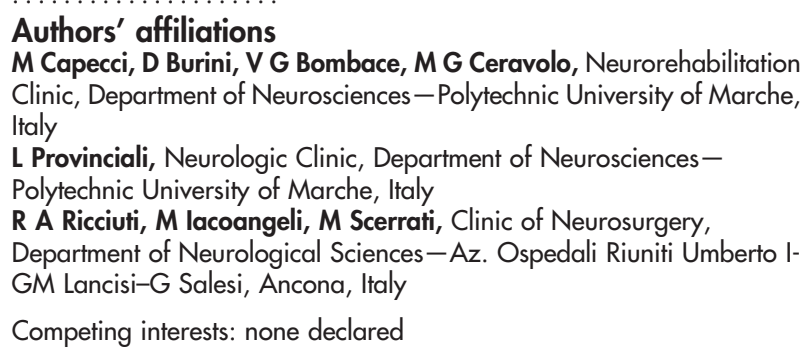

\section{Authors' affiliation}

M Capecci, D Burini, V G Bombace, M G Ceravolo, Neurorehabilitation Clinic, Department of Neurosciences - Polytechnic University of Marche, Italy

L Provinciali, Neurologic Clinic, Department of NeurosciencesPolytechnic University of Marche, Italy Department of Neurological Sciences-Az. Ospedali Riuniti Umberto ICompeting interests: none declared 


\section{REFERENCES}

1 Task force of the Movement Disorder Society. Management of Parkinson's Disease: an evidence-based review. Mov Disord 2002;17(suppl 5):S3-S386.

2 The Deep-Brain Stimulation for Parkinson's Disease Study Group. DeepBrain stimulation of the subthalamic nucleus or the pars interna of the globus pallidus in Parkinson's disease. N Engl J Med 2001;345:956-63.

3 Pollak P, Fraix V, Krack P, et al. Treatment results: Parkinson's disease. Mov Disord 2002; 17(suppl 3):S75-83.

4 Siderowf AD, Holloway RG, Stern MB. Cost-effectiveness analysis in Parkinson's disease: determining the value of interventions. Mov Disord 2000;15:439-45.

5 Spottke EA, Volkmann J, Lorenz D, et al. Evaluation of healthcare utilization and health status of patients with Parkinson's disease treated with deep brain stimulation of the subthalamic nucleus. J Neurol 2002;249:759-66.

6 Lang AE, Widner A. Deep brain stimulation for Parkinson's disease: patient selection and evaluation. Mov Disord 2002:15(17, S3):S94-S101.

7 Houeto JL, Damier P, Beijani PB, et al. Subthalamic stimulation in Parkinson's disease: a multidisciplinary approach. Arch Neurol 2000;57:461-5.

8 Deuschl G, Wenzelburger R, Kopper F, et al. Deep brain stimulation of the subthalamic nucleus for Parkinson's disease: a therapy approaching evidencebased standards. J Neurol 2003;250(suppl 1):143-6.

9 Limousin P, Krack P, Pollak P, et al. Electrical stimulation of the subthalamic nucleus in advanced Parkinson's disease. N Engl J Med 1998;339:1 105-11

10 Defer GL, Widner H, Marie RM, et al. Core assessment program for surgical interventional therapies in Parkinson's disease (CAPSIT-PD). Mov Disord 1999; 14:572-84.

11 Fahn S, Elton RL, Members of the UPDRS Development Committee. Unified Parkinson's Disease Rating Scale in Recent Developments. In: Fahn S Marsden CD, Calne DB, et al, eds. Parkinson's Disease. Florham Park, NJ: Macmillan Health Care Information, 1987:153-63.

12 Brown RG, MacCarthy B, Jahanshahi M, et al. Accuracy of self-reported disability in patients with parkinsonism. Arch Neurol 1989;46:955-9.

13 Kidd D, Stewart G, Baldry J, et al. The Functional Independence Measure: comparative validity and reliability study. Disabil Rehabil 1995;17:10-14.

14 Ramaker C, Marinus J, Stiggelbout AM, et al. Systematic evaluation of rating scales for impairment and disability in Parkinson's disease. Mov Disord 2002; 17:867-76.

15 Hariz G-M, Lindberg M, Hariz Ml, et al. Does the ADL part of the Unified Parkinson's Disease Rating Scale measure ADL? An evaluation in patients following pallidotomy and thalamic deep brain stimulation. Mov Disord 2002; 18:373-8.

16 Lang $\mathrm{AE}$, Benabid $\mathrm{AL}$, Koller WC, et al. The core assessment program for intracerebral transplantation. Mov Disord 1995; 10:527-8.

17 Beck AT, Beamesderfer A. Assessment of depression: the depression inventory. Mod Probl Pharmacopsychiatry 1974;7:151-69.

18 Folstein MF, Folstein SE, McHugh PR. "Mini-mental state". A practical method for grading the cognitive state of patients for the clinician. J Psychiatr Res 1975; 12:196-8.

19 Dubois B, Slachevsky A, Litvan I, et al. The FAB: a Frontal Assessment Battery at bedside. Neurology 2000;55:1621-6.

20 Raven JC. Guide to using the coloured progressive matrices. London: HK Lewis, 1965.

21 Spinnler H, Tognoni G. Standardizzazione e taratura italiana di test neuropsicologici. Ital J Neurol Sci 1987;6(suppl 8):8-120.

22 Caltagirone C, Gainotti G, Masullo C, et al. Validity of some neuropsychological tests in the assessment of mental deterioration. Acto Psychiatr Scand 1979:60:1-13.

23 Barcelo F, Sanz M, Molina V, et al. The Wisconsin Card Sorting Test and the assessment of frontal function: a validation study with event-related potentials. Neuropsychologia 1997;35:399-408.

24 Barbarotto $\mathbf{R}$, Laiacona $M$, Frosio $R$, et al. A normative study on visual reaction times and two Stroop colour-word tests. Ital J Neurol Sci 1998; 19:161-70

25 Moro E, Scerrati M, Romito LMA, et al. Chronic subthalamic nucleus stimulation reduces medication requirements in Parkinson's Disease. Neurology 1999;53:85-90.

26 Capecci M, Passamonti L, Annesi F, et al. Chronic bilateral subthalamic deep brain stimulation in a patient with homozygous deletion in the Parkin gene. Mov Disord 2004; 19:1450-2.

27 Volkmann J, Herzog J, Kopper F, et al. Introduction to the programming of deep brain stimulators. Mov Disord 2002;17(suppl 3):S181-7.

28 Olanow CW, Koller WC. An algorithm (decision tree) for the management of Parkinson's disease: treatment guidelines. American Academy of Neurology. Neurology 1998:50(3 suppl 3):S1-57.
29 Olanow CW, Watts RL, Koller WC. An algorithm (decision tree) for the management of Parkinson's disease (2001): treatment guidelines. Neurology 2001;56(11 suppl 5):S1-S88.

30 Ceravolo MG, Paoloni L, Provinciali L. Rehabilitation of parkinsonian patients. Funct Neurol 2001;16:157-62.

31 Hoehn MM, Yahr MD. Parkinsonism: Onset, progression, and mortality. Neurology 1967; 17:427-42.

32 Krack P, Batir A, Van Blercom N, et al. Five-year follow-up of bilateral stimulation of the subthalamic nucleus in advanced Parkinson's disease. N Engl J Med 2003;349:1925-34.

33 Rodriguez-Oroz MC, Zamarbide I, Guridi J, et al. Efficacy of deep brain stimulation of the subthalamic nucleus in Parkinson's disease 4 years after surgery: double blind and open label evaluation. I Neurol Neurosurg Psychiatry 2004:75:1382-5.

34 Ford B, Winfield L, Pullman SL, et al. Subthalamic nucleus stimulation in advanced Parkinson's disease: blinded assessments at one year follow up. J Neurol Neurosurg Psychiatry 2004;75:1255-9.

35 Stowe RL, Wheatley K, Clarke CE, et al. Surgery for Parkinson's disease: lack of reliable clinical trial evidence. J Neurol Neurosurg Psychiatry 2003:74:519-21.

36 Tandberg E, Larsen JP, Nessler EG, et al. The epidemiology of Parkinson's disease in the county of Rogaland, Norway. Mov Disord 1995;10:541-9.

37 Schrag A, Quinn N. Dyskinesias and motor fluctuations in Parkinson's disease. A community-based study. Brain 2000;123(Pt 11):2297-305.

38 Jankovic J, McDermott M, Carter J, et al. Variable expression of Parkinson's disease: a base-line analysis of the DATATOP cohort. The Parkinson Study Group. Neurology 1990;40:1529-34.

39 Louis ED, Tang MX, Cote L, et al. Progression of parkinsonian signs in Parkinson's disease. Arch Neurol 1999:56:334-7.

40 Romito MA, Scerrati M, Costantino MF, et al. Long-term follow-up of subthalamic nucleus stimulation in Parkinson's disease. Neurology 2002;58:1546-50.

41 Schwab JF, England AC. Projection technique for evaluating surgery in Parkinson's disease. In: Gillingham FJ, Donaldson MC, eds. Third Symposium on Parkinson's Disease. Edinburgh: Churchill Livingstone, 1969:152-7.

42 Movement Disorder Society Task Force on Rating Scales for Parkinson's Disease. The Unified Parkinson's Disease Rating Scale (UPDRS): status and recommendations. Mov Disord 2003;18:738-50.

43 Goetz CG, LeWitt PA, Weidenman M. Standardized training tools for the UPDRS activities of daily living scale: newly available teaching program. Mov Disord 2003; 18:1455-8.

44 Martinez-Martin P, Benito-Leon J, Alonso F, et al. Patients', doctors', and caregivers' assessment of disability using the UPDRS-ADL section: are these ratings interchangeable? Mov Disord 2003;18:985-92.

45 Biemans MAJE, Dekker J, van der Woude LHV. The internal consistency and validity of the self-assessment Parkinson's disease disability scale. Clin Rehabil 2001;15:221-8

46 Wade DT. Epidemiology of disabling neurological disease: how and why does disability occur? J Neurol Neurosurg Psychiatry 1997;63(suppl):S1 1-18.

47 Marras C, Rochon P, Lang AE. Predicting motor decline and disability in Parkinson's disease. Arch Neurol 2002;59:1724-8.

48 Burn DJ. Depression in Parkinson's disease. Eur J Neurol 2002;9(suppl 3):44-54.

49 Okun MS, Green J, Saben R, et al. Mood changes with deep brain stimulation of STN and GPi: results of a pilot study. J Neurol Neurosurg Psychiatry 2003:74:1584-6.

50 Berney A, Vingerhoets F, Perrin A, et al. Effect on mood of subthalamic DBS for Parkinson's disease: a consecutive series of 24 patients. Neurology 2002;59:1427-9.

51 Saint-Cyr JA, Trepanier LL, Kumar R, et al. Neuropsychological consequences of chronic bilateral stimulation of the subthalamic nucleus in Parkinson's disease. Brain 2000; 123(Pt 10):2091-108

52 Doshi PK, Chhaya N, Bhatt MH. Depression leading to attempted suicide after bilateral subthalamic nucleus stimulation for Parkinson's disease. Mov Disord 2002; 17:1084-5

53 Welter ML, Houeto JL, Tezenas du Montcel S, et al. Clinical predictive factors of subthalamic stimulation in Parkinson's disease. Brain 2002;125:575-83.

54 Reardon KA, Shiff M, Kempster PA. Evolution of motor fluctuations in Parkinson's disease: a longitudinal study over 6 years. Mov Disord 1999:4:605-11.

55 Rascol O, Goetz C, Koller W, et al. Treatment interventions for Parkinson's disease: an evidence based assessment. Lancet 2002;359:1589-98.

56 Goetz CG, Stebbins GT, Blasucci LM. Differential progression of motor impairment in levodopa-treated Parkinson's disease. Mov Disord 2000;15:479-84. 